\title{
STRATEGIC REGULATORY PLAN IN ING IN THE MANAGEMENT OF HAZARDOUS MATERIALS
}

\author{
Sheldon Kamieniecki and Steven A. Cohen ${ }^{1}$
}

The failure to coordinate policy formulation with policy implementation in hazardous waste regulation has hindered the identification of potential obstacles to achieving compliance. In an effort to integrate policy formulation with implementation, this paper develops a strategic regulatory planning model and applies it to a specific case, the underground storage tank provision of the 1984 Hazardous and Solid Waste Amendments. The final plan, submitted to the United States Environmental Protection Agency, emphasises 'induced compliance'. The study shows that the model provides policymakers with a practical tool for combining policy formulation with implementation and identifying possible impediments to achieving compliance.

Serious problems have resulted from a separation of policy formulation from policy implementation in hazardous materials regulation. In addition to wasted time, money, and effort, the bifurcation of the two policy processes has hindered the identification of economic, political, and other obstacles to achieving compliance and controlling pollution. As a result, delays in the attainment of programme objectives have been common. The recent tendency of Congress to transfer oversight responsibility for hazardous waste regulation from the federal government to state and local government has added new potential roadblocks (Bowman, 1984; Kamieniecki, O'Brien, and Clarke, 1986; Davis and Lester, 1987), and has made it even more critical to coordinate operationally policy formulation with policy implementation.

Obviously, the failure to obtain compliance with hazardous waste laws threatens the nation's environmental quality and, in many cases, the public health (Cohen, 1986; Marcus, 1986). If policymakers possessed a well-defined model that helped them integrate policy formulation with implementation and identify possible regulatory impediments, they would be more likely to increase compliance rates and, in turn, environmental quality. Accordingly, this paper introduces a strategic regulatory planning model for the design of regulatory programmes, and employs it in the development of an actual programme to administer a critical provision of the $1984 \mathrm{Haz}-$ ardous and Solid Waste Amendments (HSWA), the regulation of underground storage tanks (USTs). As the results will show, the study provides policy-makers with a practical tool for linking policy formulation with implementation and overcoming potential obstacles to programme success. The paper begins with a discussion of hazardous waste policy.

\section{Hazardous waste policy}

The handling and disposal of hazardous materials is a major policy issue in the United States, Europe, and many other developed and developing countries. Based on the literature, how nations address this problem largely depends upon their political and governmental system. Coppock (1986), for example, analyses how chemical risk analysis is performed in the United States, West Germany, England, France, Sweden, and Japan. $\mathrm{He}$ finds that in all countries, except the United States, regulatory policy is legitimised through some form of consultation and negotiation among relevant groups. Thus, decisions come to reflect the collective wisdom of those involved. In the United States, however, policy is based on collected evidence interpreted according to particular procedures. Instead of the administrative appeals and judicial challenges to each step in the process, which frequently occurs in the United States, the approaches of the other countries rely much more heavily on the positions of a small number of key individuals, many of whom are scientific and technical experts. Policy consensus rather than policy conflict is, therefore, more common in the 
countries studied. When concern increases, the affected industry and government agencies convene and decide upon the least disruptive course of action. The privatisation of American industry, of course, also adds tension and conflict to the decisionmaking process.

Similarly, Brickman, Jasanoff, and Ilgen (1985) examine hazardous materials regulation in the United States, France, England, and West Germany. National policies are analysed in terms of: the legal and institutional framework; the structural and political characteristics of lawmaking; the organisation and processes of administrative implementation; and the role of the courts. The researchers find that the fragmentation of political power in the United States results in greater formality, judicial intervention, and potential for extended conflict than in its foreign counterparts. At the same time, patterns of cooperation, an inclination toward closed consultation, and less judicial review lead to less divergence between conflicting viewpoints and comparatively stable compromises in the European countries studied.

In the United States, environmental regulatory programmes, if not most regulatory programmes, are often products of disjointed policymaking. Components of complex policy issues are identified, separated, categorised, and subjected to detailed analysis. A difficulty with this approach is that it sometimes focuses agencies on means and encourages them to lose sight of ends. Due to complexity, the 'whole' is so fragmented that policymakers and staff have little incentive to consider the 'big picture'. Rather than worrying about whether a regulatory programme will allow an agency to reach a legislative goal, many policymakers strive to improve the efficiency of the implementation process.

The United States Environmental Protection Agency's (EPA) hazardous waste regulatory programme is a case in point. As reflected in the Resource Conservation and Recovery Act of 1976, federal hazardous waste regulation was purely a paper exercise until 1983. For seven years EPA made numerous attempts to promulgate hazardous waste rules under the Resource Conservation and Recovery Act before finally succeeding. While these rules were being developed, hazardous waste remained unregulated by the federal government. Difficulties in promulgating regulations stemmed from legal challenges to requirements and shifts in EPA policy. EPA's Office of Solid Waste became more concerned with getting the regulatory programme 'out the door and on the street' than with improvements in environmental quality. Process and policy issues took precedence over implementation.

As stated at the outset, this study incorporates strategic thinking into regulatory planning and injects a concern for implementation into planning. Regulatory planning, however, is a disjointed and segmented process. Adding a concern for implementation cuts against the grain that establishes such policymaking practices in the first place. Nonetheless, it is advantageous for policymakers to address issues of feasibility prior to programme execution. Strategic regulatory planning is therefore potentially useful since it requires a concern for both the formulation and implementation of specific regulatory policies.

\section{Defining strategic regulatory planning}

According to Meier, 'Regulation is any attempt by the government to control the behaviour of citizens, corporations, or subgovernments' (1985, p. 1). Strategic regulatory planning is an effort by government to develop a comprehensive strategy or tactic for controlling behaviour. Hoffer and Schendel (1978) define strategy as the basic pattern of current and planned resource deployments and environmental interactions that indicate how the organisation will achieve its objectives. In strategic regulatory planning the formal regulation itself is only one component among several avail. able to control behaviour. Funding, technical assistance, exhortation, and publicity are examples of other techniques that can be used to influence the behaviour of regulated parties. Strategic planning seeks to place the promulgation of formal regulations within the context of other tools available to affect behaviour. In the broadest sense, a regulatory strategy projects the impact of government action on the organisational environment of regulated parties.

\section{A model for strategic regulatory planning} This section presents a model for strategic regulatory planning. The model encourages policymakers to approach regulation through a tactical, step-bystep process and to link policy formulation with implementation. The steps are derived from a schematic outline of political strategy formulation developed by MacMillan and Jones (1986). Research conducted by Hoffer and Schendel (1978) was also helpful in identifying specific elements of the model.

Figure 1 lists the seven major steps that should be followed in designing an effective regulatory programme. Let us take a closer look at each phase of the model. 
1. PROBLEM RECOGNITION

2. IDENTIFICATION OF PARTIES

3. HISTORICAL ANALYSIS

4. SITUATIONAL ANALYSIS

a. Mission/Objectives

b. Party analysis

\section{STRATEGIC REGULATION FORMULATION}

\section{EXANTE REVIEW}

7. EXPOSTREVIEW/REVISION
What is at issue?

Who is involved?

How have different levels of government and the parties involved responded to this issue in the past? Why?

What outcomes are desired?

What are the motivations, goals, positions, and resources of each party to either comply with, ignore, or fight the desired behavioural changes?

Determination of the conditions in the regulated community, regulating agency, and the outside arena that affect the cost and level of coerciveness of alternative regulatory devices. The most appropriate devices are then chosen to influence target group behaviour and achieve compliance.

Addresses the fit and feasibility of the regulatory plan before implementation.

Following implementation, how successful has the regulatory plan been at modifying behaviour? Is further modification needed?

Figure 1

A seven-step model for strategic regulatory planning
1. Problem recognition This step serves to focus efforts on a clearly definable problem or issue, and to provide an introduction to the question at hand. Policymakers are encouraged to identify and examine the dynamics of the problem. Admittedly, there often is a lack of information or some degree of uncertainty at the outset.

2. Identification of parties This step serves to identify all individuals and groups that are directly or indirectly involved in or affected by the problem. Among the primary classes of parties that should be examined are legislative parties (e.g. national and state legislatures), regulatory parties (e.g. national agencies, state agencies, and local officials), target groups, victim groups, and interested third parties.

3. Historical analysis Policymakers are asked to gain an understanding of the past history and seriousness of the problem, as well as the effectiveness of previous regulatory attempts at different levels of government. This step not only ensures that prior mistakes are avoided but, more importantly, identifies the underlying party motivations and external causes that precipitated prior regulatory failure.

4. Situational analysis The situational analysis phase serves two purposes. First, it identifies, conceptually and operationally, the specific goals and desired outcomes. Second, it assesses the strengths, weaknesses, resources, and motivations of each party involved. From a tactical standpoint, policymakers attempt to predict the responses of each party to the regulatory stimulus as well as explain the motivations or reasons for responding in such a manner. Public choice theory might be helpful in this regard. Meetings, documents, and surveys can provide important data during this phase of the model.

5. Strategic regulation formulation Manypolicymakers consider this step to be the most critical part of the process. Here, specific regulatory devices are selected and the actual regulatory programme takes shape. As the model implies, the more closely the selection of regulatory devices follows from and is consistent with the results of the analysis performed in the first four steps, the more likely the overall programme will be effective. Due to the importance of this stage, a conceptual framework for the selection of specific regulatory techniques is developed.

In comparison to other policy areas, regulation has a distinct goal, namely compliance. In this study 'compliance', the dependent variable, means the degree to which members of a target group conform to the directives of an agency, court, legislative body, or some other governmental unit. ${ }^{2}$ By definition, the regulatory process requires analysts to conceptualise outputs (products) and 


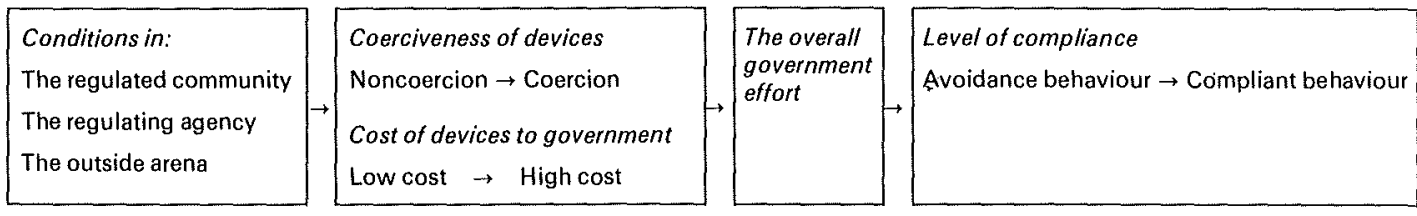

Figure 2

A conceptual framework for the selection of regulatory devices

outcomes (consequences) somewhat differently than in other policy domains (e.g. redistributive programmes).

In most cases, policymakers will want to steer the outcomes of regulatory efforts as close to compliance as possible with the least amount of coercion and at the lowest financial cost to government. Usually, the most coercive techniques (e.g. on-site inspections) will necessitate the greatest government involvement and will therefore be more expensive to oversee than the least coercive techniques (e.g. voluntary selfregulation). The presence of certain conditions, however, will tend to influence how much coercion is required and at what cost. In theory, the adoption of the most expensive and restrictive regulatory devices should guarantee a high rate of compliance. Yet, as Marcus (1980) shows, certain conditions (e.g. a poor business climate) can force outcomes toward noncompliance for even very costly and coercive regulatory techniques. In other instances, other considerations might permit the adoption of the least costly and coercive regulatory devices to achieve compliance. If environmental policymakers are to devise mechanisms to produce desired results, they must carefully read existing conditions and be alert to changes.

The three sets of conditions that exist prior to implementation and that can influence the cost and coerciveness of regulatory devices necessary to induce compliance are those in the regulated community, regulating agency, and outside arena. In the regulated community, policymakers need to pay attention to such factors as the size and diversity of the target population, the regulatory costs to target groups, amount of behavioural change required, ability to hide noncompliance, and risk preference. Among the conditions in the regulating agency that should be considered are the commitment of relevant actors, regulatory timetable, resources of the agency(ies) involved (including available funds, personnel, and expertise), and precision of the law. Examples of conditions in the outside arena include the political and economic climate, openness of the process, and decision structures and demand patterns.
Following an evaluation of the conditions surrounding the issue area, policymakers can begin analysing alternative regulatory mechanisms. Regulatory devices tend to fall at different points along a continuum of coerciveness. In other words, devices intended to control behaviour tend to vary according to their restrictiveness. Non-coercive approaches (through self-regulation) occupy one end of the continuum while coercive approaches (through direct command-and-control regulation) occupy the other end. Conceptualising regulation in these terms provides policymakers with a flexible framework in which to study alternative regulatory techniques.

Cost is a second dimension that characterises regulatory mechanisms. Cost refers to the amount of money government must spend to administer a particular regulatory approach. In general, as pointed out earlier, the most coercive activities (e.g. imprisoning polluters) require the greatest government involvement and therefore are more expensive to administer than the least coercive activities (e.g. economic incentives). Limited government revenues obviously make this an important variable.

The total cost and coerciveness of the selected regulatory programme represents the overall government effort necessary to attain compliance and control pollution. Compliance can be achieved in varying degrees and is best conceptualised along a continuum ranging from avoidance to adherence.

Figure 2 shows the relationships between different types of conditions, the non-coercion/coercion and low cost/high cost dimensions, overall government effort, and level of compliance.

The conceptual framework presented in Figure 2 is nested in step five of the strategic regulatory planning model and, in conjunction with the previous stages, fosters a concern for implementation. In more general terms, it provides policymakers with a guide for formulating a regulatory plan to meet specific legislative goals, in this case, the UST provisions of HSWA. 
6. Ex ante review The ex ante review step addresses the fit and feasibility of the selected regulatory approach before implementation. This acts to avoid wasted effort, resources, and time spent in implementing a poor regulatory programme by identifying potential trouble spots before it is too late. As flaws are singled out, policymakers should trace back through the strategic plan to the problem point and reformulate the regulatory programme using the modified knowledge base.

7. Ex post review/revision At this stage policymakers determine the effectiveness of the regulatory programme after it has been implemented. Feedback and evaluation are used to assess programme performance. The operational objectives identified in step four serve as the basis for comparison. Usually, the aim of revision (if required) will be increased compliance.

The hazardous and solid waste amendments Congress expanded the scope of the Resource Conservation and Recovery Act by enacting HSWA in 1984. This legislation regulates, for the first time, the owners and operators of over one million USTs. In contrast to previous American hazardous waste laws (e.g. Superfund), the regulation of USTs was passed without any wide. spread outcry from the public. Following the allegations of mismanagement in EPA's hazardous waste programme, Congress was searching for a vehicle to demonstrate that it was aggressively controlling toxic pollution. The revisions of the Resource Conservation and Recovery Act became a forum for demonstrating Congress's new 'get tough' policy.

HSWA is one of the most detailed pieces of environmental legislation ever written (Harris, Want and Ward, 1987). After battling over interpretations of environmental legislation during the reign of EPA Administrator Ann GorsuchBurford in the early 1980 s, Congress decided to leave nothing to chance. EPA was placed on tight schedules, and regulations were required to conform to detailed Congressional specifications. If EPA does not meet the deadlines for promulgating guidelines, Congress has included statutory 'hammer clauses' in HSWA. For the first time Congress has issued regulations that will go into effect by a specified date unless EPA adopts its own regulations. These 'regulations by statute' will most likely be much harsher than EPA's regulations. Thus, in order to avoid administrative delay, EPA has been encouraged to issue guidelines on time. Industry, in turn, understands that the result of contesting and delaying standards will be stricter standards.

In addition to tightening up hazardous materials regulation, HSWA significantly expands the number of individuals and firms subject to regulation. Prior to 1984 , toxic-bearing municipal garbage dumps, small quantity generators of hazardous waste, and UST operators were not regulated by federal law. HSWA now places all those parties under federal control.

The single most dramatic expansion of regulatory power is the provision of the law regulating USTs. Every gasoline station in America is now regulated under HSWA: (Therefore, a consumer product, gasoline, and not a hazardous waste is the primary target of the legislation.) To comply with the law's edicts some tank owners will need to replace their tanks (at a cost ranging from $\$ 10,000$ to $\$ 100,000$ ) and clean up tank leaks (at costs ranging into the millions). This authority was further expanded when Superfund was reauthorised in October 1986. The Superfund Amendments and Reauthorisation Act requires owners of USTs to carry insurance and provides EPA with a 100 million dollar a year trust fund to pay the cost of abating tank leaks. The complexity and challenge of this regulatory task is staggering, primarily because of the large and diverse size of the target group. Tens of thousands of firms are included in the UST programme, and most of these firms are small businesses with unique problems and characteristics. Management of the UST programme presents EPA with a formidable and nearly unprecedented challenge since it rarely has had to oversee a target population of this nature or magnitude. If EPA is to achieve adequate rates of compliance with the UST provisions, it will have to possess a well-defined model for the development of an overall regulatory programme. ${ }^{3}$

\section{The research project}

In December 1984, EPA's Office of Solid Waste and Emergency Response contracted with the National Academy of Public Administration (NAPA) to analyse the long-range policy issues associated with HSWA. NAPA is a Congressionally-chartered membership organisation of nearly 400 scholars and practitioners in public administration. The investigation began as a wide-ranging assessment of the legislation's purpose and administrative problems, but quickly focused on the newly regulated parties, namely the owners of USTs and small quantity generators of hazardous waste. By the time the project was 100 days old, 
however, it had principally become an effort to design a broad policy for regulating USTs.

The Hazardous Waste Management Project was guided by a panel of six Academy members and three outside experts in different fields. A staff assisted the panel in its research, deliberations, and completion of additional work requested by EPA. ${ }^{4}$ Over 10 background papers and two major strategy papers were drafted during the study. Library sources, government documents, and comprehensive surveys of involved parties furnished data for these papers (and the completion of the first four steps of the strategic regulatory planning model). Most of the background papers and both strategy papers were subjected to a thorough review by the panel and EPA management. In addition, the panel met four times to formulate recommendations and hear presentations by individuals from NAPA, EPA, interest groups, and industry. The final UST regulatory plan was unanimously supported by the Project's panel.

\section{The results}

The Hazardous Waste Management Project was conducted between 1985 and 1986 . The strategic regulatory planning model introduced earlier was followed in the study. As steps one through four require, the research staff collected a great deal of information on different facets of America's UST problem. The results of the entire investigation are summarised below.

1. Problem recognition Almost one-third of America's underground tanks are leaking because they are old and unprotected against corrosion. Many leaking USTs may pose serious risks to the environment, particularly to aquifers, and public health (Feticiano, 1984; US EPA, 1985). Benzene and ethyl dibromide, two components of gasoline, are suspected carcinogens. Releases from USTs also can contaminate surface water and can lead to fire and explosions.

\section{Identification of parties More than three} million active and abandoned gasoline storage tanks are buried underground in the United States (Blodgett and Copeland, 1985). From 600,000 to 700,000 tanks are located at over 200,000 retail gasoline outlets across the United States. It is estimated that about $50 \%$ of these are owned by major oil companies; determining ownership status for the other half is difficult. Some belong to automobile and truck rental companies and automobile, truck, and taxi fleets. Others are owned by different levels of government. Roughly
100,000 tanks contain materials other than gasoline (e.g. chemicals).

3. Historical analysis Prior to the passage of HSWA, federal legislation did not adequately regulate USTs. The Resource Conservation and Recovery Act regulates tanks which contain hazardous wastes but not tanks with petroleum or other hazardous products. However, California, Dade County in Florida (Miami), Suffolk County in New York (Long Island), and Barnstable County in Massachusetts (Cape Cod) - all areas heavily dependent upon groundwater-developed programmes to clean up and prevent leaks from both petroleum and chemical tanks prior to 1984. An ad hoc tank coalition-consisting of the American Petroleum Institute, the Steel Tank Institute, the National Oil Jobbers Council, and the Society of Independent Gasoline Marketers argued that the UST problem should be studied further before passage of federal legislation. Yet increased publicity concerning groundwater contamination, coupled with EPA's refusal to appropriate money for hazardous waste site cleanup in the early 1980 s, placed pressure on Congress and President Reagan to enact HSWA.

4. Situational analysis Subtitle I of HSWA requires EPA to develop a comprehensive programme for the regulation of USTs 'as may be necessary to protect human health and the environment' (S.9003(a)). Specific provisions of the law concern notification, interim prohibition, new tank standards, monitoring and reporting standards for existing tanks, corrective actions, financial responsibility, inspection and enforcement, and state authorisation. As noted earlier, innovative statutory 'hammer clauses' were included to minimise delay by EPA and industry. The positions and possible activities of tank manufacturers, small businesses, major oil companies, trade associations, the insurance industry, and state and local government agencies were reviewed at this juncture of the study. Research identified potential obstacles to achieving compliance, which included the nature of the regulated community, political support for regulating USTs, the availability of liability insurance, inadequate information, and the deadlines and ambiguities contained in the statute itself.

5. Strategic regulation formulation The data and information collected in the first four steps of the model provided a foundation for pursuing step five. Following the framework in Figure 2, the research staff evaluated the conditions in the regulated community, regulating agency, and outside arena that might affect the cost and coerciveness 
of regulatory devices necessary for achieving compliance. Among the regulatory devices analysed were market solutions and economic incentives, insurance programmes, self-regulation, taxes and fees, reporting and compliance tracking, licensing, permits, standard setting, setting penalties, inspections, adjudication, education, information disclosure, and the use of the media.

After considering all the constraints and potential obstacles to regulating USTs, the Project panel and research staff recommended that EPA adopt a strategic regulatory plan that emphasises induced compliance' (NAPA, 1986). There was a general belief that methods to induce compliance should be multi-faceted. As a consequence, the regulatory programme contained three principal components: stimulate voluntary compliance, stimulate private enforcement by requiring liability insurance and/or financial assurance, and implement tactical and selective high visibility enforcement procedures against violators. By suggesting that EPA stimulate voluntary compliance, the study team was calling for the agency to do all it could to encourage regulated parties to learn about tank standards, understand how those standards apply to their operations, and take steps to comply voluntarily with the law's requirements. To help promote voluntary compliance the panel and staff suggested that EPA develop education, technical assistance, and financial assistance programmes. The desire on the part of UST owners to prevent the loss of a valued product (gasoline) should facilitate the implementation of this part of the plan.

The second component of 'induced compliance' was based on the expectation that voluntary compliance would never be total and that some degree of coercion would be necessary. The panel urged the EPA to enforce aggressively the requirement that UST owners prove that they have the financial capability to abate tank leaks and pay for associated damages. It was hoped that an insurance requirement might stimulate a self-policing system based on insurance company interest in minimising and stabilising risk and on tank owner interest in obtaining insurance at the least possible cost. Specifically, EPA's role would be to ensure that tank owners actually carry some type of insurance, investigate tank leaks that have not been fixed, and enforce the law when self-regulation fails. Apparently, Congress also saw the potential value of requiring insurance when it enacted the Superfund Amendments and Reauthorisation Act soon after the final strategic regulatory plan had been submitted to EPA by NAPA.
In suggesting the adoption of the third component of the 'induced compliance' approach, the panel and staff assumed that the other two components would not be comprehensive enough and violations of the law would occur. Voluntary, selfpoliced compliance can be stimulated with a credible enforcement threat. Due to limited resources (in terms of budget and staff), such a threat will only be credible if it is selective and certain. The panel and staff believed that the United States Internal Revenue Service's model of explicit, visible, and statistically selective inspection (or audit) was worth imitating in the regulation of USTs. Even though only a tiny portion of the nation's taxpayers are audited each year, most taxpayers believe that there is a real chance they may be selected. If a similar perception could also be nurtured among tank owners, the probability of compliance should be enhanced.

The recommended strategic regulatory plan was built on the understanding that government's regulatory activities can range from assisting voluntary compliance to active and vigorous enforcement. As explained before, these are two ends of what can be termed a non-coercive/ coercive continuum. In the case of regulating USTs, the idea was to adopt a mix of coercive and non-coercive mechanisms that were costeffective and that promote compliance.

6. Ex ante review Throughout the early 1980s, insurance companies reduced offerings or dramatically increased the price of certain types of liability insurance. As a result, municipalities, medical doctors, environmental facilities, and other organisations faced serious difficulties obtaining insurance. In 1985, environmental liability insurance became particularly difficult to purchase.

Clearly, it is beyond EPA's jurisdiction to alleviate the liability insurance crisis. If insurance is unavailable, this particular component of the induced compliance' regulatory approach cannot be fully employed. Even if the insurance problem can be resolved, it is difficult to expect the insurance industry to cover every tank that is currently leaking.

For EPA to implement successfully this component of the plan, the insurance problem needs to be solved. The panel and staff recommended that EPA work with Congress to address the issue of tort liability (NAPA, 1986). They advocated that either liability limits or some type of regulatory mechanism should be considered to assure the availability of reasonably priced environmental 
insurance. The Agency was also advised to work with the insurance industry to overcome technical uncertainties regarding risk prediction. EPA could help identify low-risk and high-risk tanks to facilitate risk-based insurance pricing.

Furthermore, EPA was advised to back up the insurance requirement with a strong administrative mechanism for monitoring compliance. For tanks that are uninsurable, the panel and staff suggested that EPA work with the states to develop assigned risk pools or Superfund-type fee systems to pay the cost of cleanup. Such a mixed public-private insurance system might assure that all tank leak cleanups have a source of funding. The key challenge to EPA in implementing this approach was to keep insurance companies in the market and competitive. A second challenge was to induce these companies to monitor tank management practices and structure insurance rates according to risk. The panel and staff were aware of the difficulty of accomplishing these goals but considered them worthy of significant effort (NAPA, 1986). ${ }^{5}$

Moreover, beginning in 1988, states are eligible to apply for authorisation from EPA to operate a UST programme in lieu of the federal programme. (Until then enforcement is a federal responsibility.) Thus, EPA's primary role is to prepare state and local governments for their lead role in enforcing underground tank regulations. In order to ensure that state and local governments assume this function, the panel and staff advised EPA to stimulate public support for enforcement efforts. They also suggested that EPA provide state and local governments with guidance on inspection and litigation procedures and with limited grant funding to seed state efforts. In addition, it was recommended that the Agency play a clearinghouse role in exchanging case development lessons and emerging precedents. Finally, the panel and staff advised EPA to take the lead in publicising enforcement efforts in order to build the regulated community's perception that violators would be punished.

EPA was advised to work actively to generate public support for the enforcement of UST provisions for a second reason. Enforcement directed against small businesses run by 'average' people entails different political risks than enforcement against larger, 'faceless' corporations. It is easy for a federal regulatory agency to appear unreasonable when suing small businesses. It is important, therefore, to select initial enforcement targets carefully and to make certain that the Agency's case against the violator is clearly communicated to the public. *

7. Expost review and revision This last phase of the planning process takes place after implementation has begun and enough experience has been gained to gauge the success of the programme. There are three purposes for this review: (1) To assess the degree to which implementation has conformed to the original design; (2) To assess the adequacy and current relevance of the original plan; and (3) To suggest mid-course corrections in the regulatory programme. Since the EPA has had little time to adopt and implement the plan, it will be difficult to draw definitive conclusions about the overall success of the programme, especially where rates of compliance are concerned. In fact, accurate data on level of compliance in each state may not be available for a number of years. The discussion, therefore, focuses on the first two objectives and not on the third one.

The original organisation structure of the new Office of Underground Storage Tanks closely adhered to the panel and staff's recommendation. Initially, one of the new office's two units was a branch designed to focus on implementation issues. EPA's intention to focus on these type of issues was reinforced by a major reorganisation of the Office of Underground Storage Tanks in the spring of 1987. With the passage of the Superfund Amendments and Reauthorisation Act in 1986 and the establishment of a UST trust fund, a third branch was added to the Office of Underground Storage Tanks devoted to administering the fund. It soon became apparent, however, that the corrective action or cleanup effort had been divided into two parts that needed to be combined. The functions of preventing tank leaks and enforcing private cleanup of tank leaks were in one unit. The function of trust fund-financed cleanups was coordinated by a second unit. The addition of a trust fund branch created a hybrid structure. Two of the three branches were organised by functions (policy development and implementation), while one was organised by legislation (the Superfund Amendments and Reauthorisation Act). The function of implementing the regulatory aspects of the programme would benefit by combining them with the resources and high-level attention generated by the trust fund. For that and other reasons, the Office of Underground Storage Tanks was restructured into a Policy Division, an Implementation Division, and a Deputy Director for Programme Management. This reorganisation 
allowed the office to continue its effort to concentrate on implementation activities.

From July through October 1986, the Office of Underground Storage Tanks developed a programme budget for the 1987 financial year. ${ }^{6}$ The Programme Budget of the Office of Underground Storage Tanks described the organisation's objectives and activities for the 1987 financial year and summarised spending and personnel allocations for each of 75 proposed projects. More than half of the office's contract funding (53.2\%) and over one third of its staff time (35.8\%) was allocated to implementation. Regulation development received about a quarter of the organisation's personnel $(25.4 \%)$ and contract funding (29.1\%). These figures are particularly striking in a new regulatory organisation where presumably a number of new regulations must be promulgated before implementation can even begin. The Programme Budget is another indication of the intention of the Office of Underground Storage Tanks to link policy formulation with implementation, a key objective of the strategic regulatory planning model.

If budgets and organisational structures reflect organisational behaviour, one can conclude that the Office of Underground Storage Tanks has adhered to one of the basic principles of the strategic regulatory plan; the emphasis on inducing compliance. However, the plan contained additional recommendations. The panel and staff also suggested that EPA work closely with interest groups to encourage compliance, require tank insurance, and strategically enforce tank laws. The Agency has begun an active programme of interest group relations. Yet, with the passage of the Superfund Amendments and Reauthorisation Act, Congress (and not EPA) required owners of USTs to have insurance. As time goes on, EPA plans to involve state and local governmental entities in a coordinated effort to verify that tank owners and operators are complying with the law.

The difference between the panel and staff's recommendations and actual EPA behaviour was due to deliberate policy or management choices, the effect of EPA standard practices, and changed conditions. There was also a fair measure of simple inattention to the recommendations. Initially, the Office of Underground Storage Tanks decided to emphasise programme development before implementation and devoted most of its resources to designing the programme. In large measure this meant developing the regulations and guidelines needed to begin the programme. Insurance for USTs was not required because the Office of
Underground Storage Tanks decided to first conduct a study of its availability and utility before mandating it. Before the issue was fully studied by the office, however, Congress decided to require insurance.

\section{Conclusion}

This paper introduced a strategic regulatory planning model for use in the management of hazardous materials. The model presented in this study contained seven steps and was applied in the design of a strategic regulatory plan for the administration of the UST provisions of HSWA. The model's simple, straightforward approach should facilitate its use in other hazardous waste programmes, and perhaps in other areas of regulation (e.g. transportation safety and consumer protection). While the model was applied at the start of a new regulatory programme, nothing about the model necessarily prevents it from being adopted at any point in a regulatory effort. It should be noted, of course, that much of the strategy of any public programme is already included in its enabling legislation.

The perspective taken in strategic regulatory planning runs counter to general tendencies in regulatory policymaking. In contrast to common practices, strategic regulatory planning necessitates the collection of substantial amounts of data and information regarding the circumstances surrounding a given issue. Rather than being disjointed and remedial, strategic regulatory planning emphasises rapid institutional learning. Lessons learned are factored into policymaking as rapidly as possible. This process is characterised by continuous feedback, evaluation, and correction, with progress (i.e. increased compliance) as the objective. In this sense, policymakers are urged to set realistic goals, and attempt to build slowly effective ways of reaching those goals. They are encouraged to move toward solutions rather than away from problems, but are not encouraged to believe that a single master plan can ever be used to accomplish a broad aim.

In summary, strategic planning requires policymakers to take a tactical approach in developing regulatory programmes. They are encouraged to study carefully the entire policy context before deciding upon a course of action. The crafting of good public policies necessitates consideration of all facets of the problem without prejudice. The model introduced in this study, while far from being perfect, encourages policymakers to do exactly that. 


\section{NOTES}

1. The authors are involved in a series of research projects on this subject. The order in which their names appear is rotated.

2. As will soon become evident, it is assumed that compliance by polluters leads to improved environmental quality.

3. See Harris, Want and Ward (1987) for a comprehensive explanation and interpretation of HSWA.

4. Cohen was the Director of the Project and Kamieniecki served as a Senior Research Consultant.

5. See NAPA (1986) for an in-depth analysis of the UST insurance issue. Also, consult Ferreira (1982) about the use of insurance as a regulatory tool.

6. Cohen worked closely with the Office of Underground Storage Tanks to develop this programme budget. However, he was no longer associated with NAPA by this time.

\section{REFERENCES}

Blodgett, J. and Copeland, C. (1985) 'Environmental protection issues of the 99th congress', Congressional Research Service, Environment and Natural Resources Policy Division Report No. 85-517.

Brickman, R., Jasanoff, S. and llgen, T. (1985) Controlling chemicals: the politics of regulation in Europe and the United States, Ithaca, N.Y.: Cornell University Press.

Bowman, A. (1984) 'Intergovernmental and intersectoral tensions in environmental policy implementation: the case of hazardous waste', Policy Studies Review 4, November, pp. 230-244.

Cohen, S. A. (1986) 'EPA: a qualified success', in Kamieniecki, S., O'Brien, R. and Clarke, M. (eds), Controversies in environmental policy, Albany: State University of New York Press, pp. 174-195.

Coppock, R. (1986) 'Chemical risk analysis: a comparison of public and private sector assessment', in Schnaiberg, A., Watts, N. and Zimmerman, K. (eds), Distribution conflicts in environmental resource policy, London: Gower Publishing Co., pp. 176-186.

Davis, C. and Lester, J. (1987) 'Decentralizing federal environmental policy: a research note', Western Political Quarterly 40, September, pp. 555-565.

Ferreira, J. (1982) 'Promoting safety through insurance', in Bardach, E. and Kagan, R. (eds), Social regulation. strategies for reform, San Francisco: Institute for Contemporary Studies, pp. 267-288.

Feticiano, V. (1984) 'Leaking underground storage tanks: a potential environmental problem', Congressional Research Service, January 11

Harris, C., Want, W. and Ward, M. (1987) Hazardous waste: confronting the challenge, Westport, Conn.: Greenwood Press.

Hoffer, C. W. and Schendel, D. (1978) Strategy formulation: analytic concepts, St Paul, Minn.: West.

Kamieniecki, S., O'Brien, R. and Clarke, M. (1986) 'Environmental policy and aspects of intergovernmental relations', in Morgan, D. and Benton, J. E. (eds), Intergovernmental relations and public policy, Westport, Conn.: Greenwood Press, pp. 49-61.

MacMillan, I. and Jones, P. (1986) Strategy formulation: power and politics, 2nd edition, St Paul, Minn.: West.

Marcus, A. (1980) 'Command and control: an assessment of smokestack emission regulation', in Brigham, J. and Brown, D. W. (eds), Policy implementation: penalties or incentives? Beverly Hills: Sage Publications, pp. 209-226.

Marcus, A. (1986) 'EPA's successes and failures', in Kamieniecki, S., O'Brien, R. and Clarke, M. (eds), Controversies in environmental policy, Albany: State University of New York Press, pp. 153-173.

Meier, K. (1985) Regulation: politics, bureaucracy, and economics, New York: St Martin's Press.

National Academy of Public Administration (1986) A strategy for implementing federal regulation of underground storage tanks, Washington, DC: National Academy of Public Administration.

United States Environmental Protection Agency, Office of Water (1985) 'Leaking underground storage tanks', April.

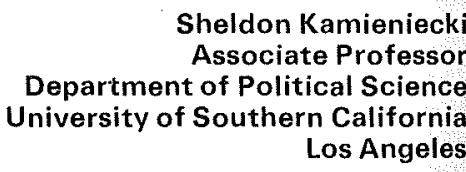

Steven A. Cohen Director

Graduate Program in Public Policy and Administration Columbia University New York 